\title{
MS 6.-9. Yüzyıllarda Bizans ve Avarlar: Siyasi, Diplomatik ve Kültürel İlişkiler
}

\section{Byzantium and The Avars 6th-9th Century AD: Political, Diplomatic and Cultural Relations}

Georgios Kardaras, Byzantium and The Avars 6th-9th Century AD: Political, Diplomatic and Cultural Relations, Leiden-Boston: Brill 2018, 189 sayfa. ISBN: 978-90-04-38226-8

Aybüke Özcan' ${ }^{1}$ (1)

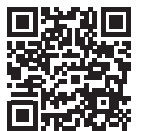

'Sorumlu yazar/Corresponding author: Aybüke Özcan (Yüksek Lisans Öğrencisi), İstanbul Üniversitesi, Sosyal Bilimler Enstitüsü, Tarih Anabilim Dalı, İstanbul, Türkiye. E-posta: aybukeozcan96@gmail.com ORCID: 0000-0002-7786-3205

Başvuru/Submitted: 22.01.202

Kabul/Accepted: 27.03.202

Atıf/Citation: Ozcan, Aybuke, "MS 6.-9.

Yüzyıllarda Bizans ve Avarlar: Siyasi,

Diplomatik ve Kültürel İlişkiler." (Kitabiyat).

Güney-Doğu Avrupa Araştırmaları Dergisi, 37 (2021), s. 157-163

https://doi.org/10.26650/gaad.1866809
Anahtar Kelimeler: Avarlar, Bizans İmparatorluğu, Siyaset, Diplomasi, Kültür

Keywords: Avars, Byzantine Empire, Policy, Diplomacy, Culture 
Eser; önsöz (s. IX), şekil ve haritaların listesi (s. X), kısaltmalar (XI), harf çevirisi üzerine bir açıklama (s. XXIV), giriş (s. 1-19) ve buna ilaveten altı bölümden oluşmaktadır. Geniş bir bibliyografyadan istifadeyle kaleme alınmış çalışmada muhtelif Doğu ve Batı dillerindeki araştırmalardan da faydalanılmıştır. Eser ilk olarak Yunanca To Vyzantio kai hoi Avaroi, 6.9. ai.: politikes, diplomatikes kai politismikes scheseis (To Buלávtı kaı o 'Aßapo ( $\sum \tau^{\prime}-\Theta$ ' aı.).

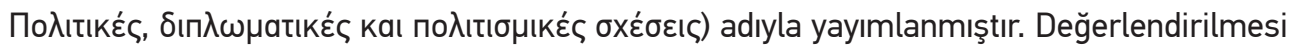
yapılan bu versiyonu ise daha sonra İngilizceye çevrilmiş ve çeşitli güncel bilgilerin eklendiği çalışmanın revize edilmiş hâlidir. Yazar bu durumu önsözde, iki basım tarihi arasında geçen yaklaşık 10 yıllık süreçte Orta Avrupa'daki meraklı araştırmacılar sayesinde Avarlar ile ilgili birçok yeni bilginin ortaya çıkması ve çıkmaya da devam etmesiyle izah etmektedir.

Müellif giriş kısmında (s. 1-19) Denis Sinor'un “Avarlar tarihi henüz yazılmamıştır” sözüne katıldığını belirtirken, Avarlar hakkındaki araştırmaların yetersiz kaldığını fakat son yıllarda yapılan birçok çalışmayla durumun değiştiğini ifade etmektedir. Bizans ve Avarlar arasındaki ilişkileri tafsilatlı bir biçimde sunmak amacıyla yazılan eserde; 558-626 yılları arasını inceleyen çalışmaların aksine 626 yılından sonra kendileri hakkında yeterli yazılı kaynak bulunmayan Avarların özellikle bu yıldan itibaren yaşadığı gelişmeler arkeolojik bulguların ışı̆ında ele alınmıştır. Müellif bilhassa hangi konuların üzerinde duracağını, Avarlar hakkında araştırma yapmak isteyenlerin ne tür hususlara dikkat etmesi gerektiğini ve bunların ehemmiyetini belirtmektedir. Üç başlığa ayrılan giriş bölümünün ikinci faslında ise Bizanslıların Avarlara olan bakış açısı; onların diğer göçebe topluluklar gibi “barbar, açgözlü, güvenilmez, zalim” gibi sözcüklerle tanımlamalara tabi tutulduklarını; kaynaklarda onlara yalnızca askerî ve siyasi bahislerde yer verildiğini, Bizans kaynaklarında Avarlara ekonomik olarak neredeyse hiç değinilmediğini ifade etmektedir. Üçüncü fasılda, Avarların Orta Asya'da yayılma süreci yanında Avrupa'ya (Batı'ya) olan göç, istila hareketlerinin sebepleri ve aşamaları, diğer kabilelere olan etkileri ve menşeleri üzerine değerlendirmeler yapılmıştır. Aynı zamanda Avarların tarihsel sürece göre değişen ve gelişen hâkimiyet sahaları irdelenmiştir.

Çalışmanın 558'den 582'ye Bizans ve Avarlar isimli birinci bölümü (s. 20-42) dört alt başlıkta incelenmiş olup, Avarların askerî sahadaki faaliyetleri neticesinde Avar Kağanlığı'nın kuruluş sürecini, dönemin Bizans imparatorları ile olan bahsi geçen yıllardaki diplomatik ilişkilerini ve Bizans'ın kuzey sınırlarındaki politikasını içermektedir. Kitabın ana konusunu ihtiva eden Kafkas Dağlarında yaşayan Avarlar ile Bizans İmparatorluğu arasındaki ilişkilerin resmî bir hüviyet kazanması 558 yılına dayanmaktadır ve Avarların Kandikh ismindeki bir elçiyi Bizans İstanbul'una göndermeleriyle başlar. Bizans İmparatoru I. Justinianos (527-565) hükümdarlığı sırasında, imparatorluk topraklarını Bizans aleyhtarı olan ve imparatorluğun kuzey hududunda faaliyet gösteren göçebe kavimlerin saldırılarından korumak için Avarlardan istifade etmeye çalışmıştır. Müellifin zaman zaman vurgusunu yaptığı en önemli hususlardan birisi de Avarların bu hizmetlerine mukabil Bizans'tan yıllık vergi, muhtelif hediyeler ve kendilerine yerleşim yeri tahsis edilmesi talebidir. Eserde, İmparator I. Justinianos'ta olduğu gibi II. Justinos (565-578) 
döneminde de gerçekleştirilen fakat neticesiz kalan müzakereler neden-sonuç bağlamında ayrıntılı olarak incelenmiştir. Öte yandan Bizanslıların Göktürk Kağanlığı ile olan münasebetlerine, İpek Yolu'nun birçok kent merkezine olan kültürel ve ekonomik tesiriyle Çin ipeğine erişimin artan önemine değinilmiştir. Bizans'tan vergi ödemeleri hususunda beklediği itibarı göremeyen Avarların Batı'ya tevcihi, 562 ve 566 yıllarında Franklarla yapmış oldukları savaşlar hakkında da bilgi verilmiştir. Bizans İmparatorluğu'nun kuzey sınııında birçok radikal değişikliklere sahne olan 566-568 yılı olayları arasında Gepidler ile Lombardlar (568-774) arasındaki mücadele de zikredilmektedir. Lombard Hükümdarı Alboin' in (568-572) Avar Hükümdarı Bayan Han'a (562-602) cazip bir ittifak teklifi sunması ve iki taraf arasında müttefiklik tesis edilmesiyle Gepidlerin egemenliğine son verilmiş; Lombardlar ise İtalya'ya gitmişlerdir. Pannonia bölgesini ele geçirmeyi başararak yerleşim imkânı yakalayan ve böylece diğer kavimlerden çok daha tehlikeli olduğu ortaya çıkan Avarlar, Orta Avrupa'da kağanlık kurarak Bizans'ın Tuna Nehri'nin kuzeyindeki tek komşuları hâline gelmişlerdir. Siyasî manada temel gayesi Bizans İmparatorluğu ile barışçıl ilişkiler yürütmek olan Avarlar diğer yandan düzenledikleri saldırılarla İstanbul'u yıllık vergiye bağlamayı hedeflemişlerdir. Yazar, eserin üçüncü alt başlığını teşkil eden olaylar arasında Balkanlar için jeopolitik ve jeostratejik yönden oldukça mühim olan Sirmium'un, İmparator II. Justinos ile Avarlar arasında yaratıı̆ı ihtilafa değinmiştir. Diğer taraftan 574 ylında Imparator Tiberius (574-582) ile Avarlar arasında imzalanan antlaşmayla Bizans'ın Avarlara sabit bir miktar para ödemeyi ilk kez kabul ettiği somut veriyi zikretmiştir. Nitekim bu anlaşma taraflar arasında takribi beş yıllık bir durgunluk evresini de beraberinde getirmiştir. Eserin ilk bölümünün son kısmında ise Doğu'da Perslerle olan muharebelerine ilaveten Slavların Balkan topraklarına saldırıları karşısında zor durumda kalan Bizans'ın Avarlar ile Slavlara karşı ittifakı ele alınmıştır. Bu safhanın daha önce de bahsedildiği üzere Sirmium üzerindeki hâkimiyet mücadelesi ile bozulduğu; Avarların bölgeyi ele geçirmesiyle sonuçlandığı bilgisi de ilmî verilerle kaydedilenler arasındadır.

Eserin 582'den 626'ya kadar Bizans ve Avarlar isimli ikinci bölümü (s. 43-87) yedi alt başlıkta incelenmiştir. İlk kısım, Sirmium'un kaybının ardından Balkan topraklarında savunma sistemi zayıflayan Bizans'in 582 yilında tahta geçen imparatoru Maurikios (582-602) ile Avarlar arasındaki münasebetlerin 591 yılına kadarki durumunu ortaya koymaktadır. Bunu takip eden ve üç bölümde aktarılan kısımlar ise Bizans İmparatorluğu'nun 591 yılı sonbaharında noktaladığı Sâsânîlerle (226-651) olan muharebenin ardından Balkan coğrafyasında Avarlar ile Slavlara yönelik yürüttüğü mücadeleleri ihtiva etmektedir. Eser, taraflar arasında yaşanan çatışmalara ek olarak diplomatik temasların da sürdüğü bu dönemi, özellikle 570 yılı itibariyle iktisadi problemler yaşayan ve ordusunu finanse etmekte yetersiz kalan dolayısıla da halkın ve askerî birliklerinin hoşnutsuzluğuna sebep olan Bizans yönetiminin İmparator Maurikios hükümdarlığındaki politikasını, yaşadığı krizleri ayrıntılı bir şekilde aktarması açısından önemlidir. Maurikios'un tahttan indirilmesinin akabinde iktidara gelen Phocas'ın (602-610) hâkimiyet devrinde, Sâsânilere karşı savaşların yeniden başlaması üzerine Avarların yıllık 
vergisinde artışa gidilerek barış sağlamaya çalışıldıysa da Avar ve Slav saldırılarının önüne geçilememiştir. Phocas'ın zalim yönetiminin ardından halefi Herakleios (610-641) başa geçmiş ve yazar tarafından hem Doğu'da hem de Balkanlarda güçlü düşmanlarla baş etmek mecburiyetinde olan Bizans'ın kaotik bir ortama sürüklenişi ele alınmıştır. Tuna sınırındaki Bizans hâkimiyetinin kademeli olarak çöküşü ile Balkan illerinin düşüşünün konu edildiği eserin bu bölümünde dikkat çeken bir başka nokta da Avarların desteğini elde eden Slavların olumsuz neticelenen Selanik kuşatmasıdır (617/618). Yazar burada anlatılan hadiseleri, ana kaynak niteliğindeki Aziz Demetrius'un Mucizeleri (Miracula Sancti Demetrii) isimli eserde geçen kayıtlardan istifade ederek okuyucuya sunmuştur. Altıncı alt başlıkta ele alınan konuda ise Bizans kaynaklarında hakkında bilgi bulunmayan, Slavların Avarlara karşı gerçekleştirdikleri, Batılı kaynaklar tarafından 623/624 yılına tarihlendirilen Samo İsyanı'nın sebeplerine ve bu hadiseye dair çeşitli uzmanların görüşlerine yer verilmiştir. Bizans-Avar çekişmelerinin son basamağını oluşturan kısım (s. 82-87) İmparator Herakleios'a barış vaadiyle kurulan tuzak ve dönemin en önemli hadisesi olarak da addedebileceğimiz Avar-Sâsânî birliklerinin İstanbul kuşatmasıdır (626). Avarların Avrupa'da bulundukları süre zarfındaki şüphesiz en önemli askerî girişimi olan bu kuşatma, Sâsânî İmparatorluğu ile müşterek gerçekleştirilmiştir. Zorlu rakipleri karşısında kanlı çarpışmalara maruz kalan ve müzakere yoluna başvuran Bizans'ın izlediği yol, hedefi imparatorluğun zenginliklerine ulaşmak olan Avarların askerî sahadaki stratejisi ve kuşatmanın akıbeti hakkında detaylı malumatlar verilmiştir.

Çalışmanın 626'dan sonra Bizans-Avar Iliş̧kileri başlıklı üçüncü bölümünde (s. 88-102) Avarlara, başarısız İstanbul kuşatmasının ardından 626 yılından itibaren tarihî kaynaklarda ne zaman ve hangi sebeplerle rastlandığı incelenmiştir. Bununla birlikte Orta Avrupa'dan Balkan topraklarına gelen Hırvatlar ile Sırpların göç dalgası, yerleşim alanları ve etnik kökenlerine dair değerlendirmeler yapılmış; konuyla ilgili diğer uzmanların iddialarına da yer verilmiştir. Müellifin Bizans-Avar siyasi ilişkileri başlığı altında dikkate değer ifadelerinin bulunduğu bir başka mevzu ise Onogur Bulgarlarının lideri Kubrat'ın (632-638) isyanıdır. Eserde İmparator Herakleios ile Kubrat arasındaki diplomatik ilişkilerin yanı sıra rastlantı sonucu erişilen ve 635 yılında teşekkül eden Büyük Bulgar Devleti'nin kurucusu Kubrat'a ait olduğu düşünülen bir mezardaki bulguların yorumlaması yapılmıştır.

Müellif eserinin Bizans-Avar İlişkilerinde Arkeolojik Bulgular adlı dördüncü bölümünde (s. 103-134) Avar tarihini erken, orta ve geç olmak üzere tasnif ederek incelemiştir. Bizans'ın Avarlar üzerindeki kültürel tesir ve karşılıklı etkileşimlerinin daha etraflı bir şekilde anlaşılmasına büyük ölçüde katkı sağlayan arkeolojik bulgulara yer verilmiştir. Avarların ölü gömme gelenekleri, sosyal statü göstergesi olan kemer tokaları ve bunların ham maddeleri, kadın mezarlarından elde edilen altın ve gümüş takılar, çanak-çömlek formlarının tasvirleri ayrıntılı olarak zikredilmiştir. Erken Avar döneminde, toplumsal tabakalaşmanın bir göstergesi olan zengin Avar mezarlarına geç dönemde rastlanmadığını belirten yazar, VIII. yüzyıl boyunca Orta Avrupa'daki en geniş sınırlarına ulaşan Avarların demografik yapısında ve iktisadi duru- 
munda yaşanan değişiklikler hakkında fikirlerini yine arkeolojik bulgularla temellendirerek sunmaktadır. Bizans-Avar ilişkilerinde aydınlatıcı rol oynayan ve göz ardı edilemeyecek derecede mühim bir öğe de paralara ait bulgulardır. Eserde, Avarların vergi yoluyla temin ettiği Bizans paralarının bölgelere ve imparatorların hâkimiyet dönemlerine göre dağıımından söz edilmektedir. Son olarak da Avar Kağanlığ'na ait kalıntılarda görülen Hristiyanlık sembolleri ile hayvan figürleri üzerinde durulmuştur. Nitekim Hristiyanlık sembolleriyle süslenmiş nesnelerin, yapılan ticari faaliyetler, verilen armağanlar ve düzenlenen saldırılar sonucu ele geçirilen ganimetler dolayısıla Avar topraklarında bulunması, onların tarihleri boyunca bu dini kabul edip etmedikleri tartışmasını da beraberinde getirmiştir.

Araşıırmanın 626 Sonrası Bizans Buluntuları ve Bizans ile Avarlar Arasında Olası Iletişsim Kanalları isimli beşinci bölümünde (s. 135-155) Bizans ile Avarların 626-660 yılları arasındaki ilişkilerine dair tek kanıtın yalnızca 634/635'te gönderilen Bizans elçiliği olduğu belirtilmiştir. Bu sebeple, üç döneme kategorize edilen çalışmada Bizans kültürünün Avar Kağanlığı üzerindeki etkisinin iki tarafın sürekli iletişimiyle bağdaştırılamayacağı, ilk ve orta Avar dönemlerine ilişkin bu durumun Avarların Bulgarlar ile olan askerî çatışmaları ve yaşanan Bulgar göçüyle ilgili olduğu aktarılmıştır. Geç Avar dönemi diye adlandırılan yıllarda ise Orta Avar döneminde olduğu gibi Bizans'ın Avarlarla sınırının ve VIII. yüzyılda yeniden yapılandırılan siyasi ilişkilerinin yazııı bir kanıııın bulunmadığı ifade edilmiştir. Bizans-Avar ilişkilerinde bu yıllardan itibaren potansiyel etkileşimin İstriya bölgesinde gerçekleşmiş olabileceği üzerinde durulmuş ve bu bölge hakkında geniş bilgiler sunulmuştur. Öte yandan Bizans İmparatorluğu ve Lombard Krallığı ilişkileri bağlamında Bizans'ın Avarlarla muhtemel temasından söz edilmiştir. Orta Avar dönemine tekabül eden ve son Avar elçilik heyetinin 678'de Konstantinopolis'e gitmesinden üç yıl sonra kurulan Birinci (Asparuh) Bulgar Devleti'nin Bizans-Avar ilişkilerindeki etkisi üzerine değerlendirmeler de yapılmıştır. Burada VIII. yüzyıl Bizans-Avar ilişkilerinin incelenmesinde en mühim unsurlardan biri olan Bizans İmparatoru III. Theodosius (715-717) ile Bulgar Hükümdarı Kormesios (716/721-728) arasında imzalanan 716 ylındaki antlaşmanın önemi vurgulanmış ve bu antlaşmanın ekseriyetle ticari ve ekonomik yansımalarından söz edilmiştir. Anlatılanlara ek olarak, Bizans kültürel motiflerinin Avar Kağanlığı́na aktarılmasının bir diğer yolu olarak görülen, Karadeniz' in kuzeyinden Orta Avrupa'ya açılan ticaret ağı Kırım idi. Bizans'ın dünya ile ticareti ise Kırım'da kontrol sahibi olduğunu iddia eden ve Kuzey İpek Yolu'nun batısında konumlanan Hazarlarla ilişkisine bağlıydı. Hazar Kağanlığı VII. yüzyılın ortalarından başlayarak 300 yıl boyunca İpek Yolu arterlerinin kilit merkezlerini kontrol etti. Müellif bu bölümde ipeğin Bizans'ın kendisine ve kendisinden de diğer coğrafyalara taşınmasını güvence altına almak için Hazarlarla iyi ilişkiler kurduğunun şaşırtıcı olmadığını ifade ederken VII. ve VIII. yüzyıla tarihlenen Çin ve Soğd ipeklerine Kuzey Kafkasya'da kazılan definlerde rastlandığını ve bu durumun İpek Yolu'nun kaynaklarda belirtilmeyen öneminin açık bir göstergesi olduğunu belirtmiştir. Avar sanatında gözlemlenen Bizans eserleri veya motiflerinin yanı sıra madenî para bulguları ise Bizans ve Avarlar arasındaki temasların 
iyi bir şekilde devam ettiğini göstermektedir. Arkeolojik kanıtlar/bulgular, kültürel ve ticari münasebetlerin büyük bir kısmını ispatlar niteliktedir.

Eserin Bizans-Avar iliş̧kileri ve Harp adını taşıyan altıncı bölümünde (s. 156-181) Bizans ve Avar ilişkilerinin en mühim yönlerinden birisi olan silahlanma mevzusu ele alınmıştır. Avar atlıları ile Bizans süvarilerinin giyim kuşamı ve savaş ekipmanları hakkında detaylı bilgiler sunulmuştur. Bu hususta müellifin eserini kaleme alırken sıkça faydalandığı Strategikon adlı eserin konunun araştırılmasındaki önemi belirtilmiştir. Bizans İmparatorluğu'nda Hunlar ve Bulgarlardan alınan paralı askerler ile temasın bir getirisi olan askerî teknolojideki gelişmeler Bizans ordusunun etkinliğini arttırdı; zaferlerine büyük katkılar sağladı. Yazar burada okçuluk kavramının Bizans içindeki ehemmiyetini ise kaynaklar vasıtasıyla ele almıştır. Bunlara ilave olarak Sâsânîlerin askerî teçhizatları ve silahları hakkında bilgiler verilerek, bunların Bizans ordusundaki etkilerinden bahsedilmiştir. Müellifin değindiği diğer bir nokta ise Avrupa'ya Avarlar tarafından tanıtıldığına inanılan üzengidir. Strategikon'daki Avarların tarzlarına ilişkin bilgiler; ağır zırhlı süvarilerin giyimi, atların donanım malzemeleri, seferlerdeki çadırlar ve bunların Bizans ordusu üzerindeki etkileri ayrı bir başlıkta teferruatı olarak incelenmiştir. Bizans ordusunun savaştaki dizilimi, düşman kuvvetlerinin niteliklerine göre belirlenen harp stratejileri, göçebe kavimlerden öğrendikleri savaş teknikleri genel olarak bu bölümün içeriğini oluşturmaktadır. Kuşatma zanaatı adı altında, kullanılan savaş aletlerinin özellikleri, Avarların müstahkem Bizans şehirlerini kuşatabilecek askerî teknolojiyi ne zaman ve ne şekilde edindiklerine dair hususlar kaynakların verdiği bilgiler ışığında irdelenmiş, araştırmacıların görüşleri ele alınmış ve bilgiler arkeolojik verilerle desteklenmiştir.

Sonuç bölümünde (s. 182-189) eserin hülasası niteliğinde bilgiler yer almaktadır. Akabinde ise şekiller (s. 191-195), haritalar (s. 196-200), yazarın faydalandığı zengin kaynak ve araştırma eserleri ihtiva eden bibliyografya (s. 201-237) ile okura kolaylık sağlayan isim ve yerlerin indeksi (s. 238-251) bulunmaktadır.

Müellif, şimdiye kadar siyasi, askerî ve diplomatik yönleriyle ele alınan Bizans-Avar ilişkilerinin göz ardı edilen kültürel boyutunu, yazılı ve görsel materyalleri ustalıkla kullanarak tafsilatlı bir çalışma ortaya koymuştur. Nitekim bu husus eseri önceki yayınlardan ayırt etmektedir. Yazar yalnızca bunlarla yetinmeyerek arkeolojik kazılar sonucu elde edilen bulguları, edebî eserleri, imal edilen gereçleri, dönemin tasvirlerini, savaş stratejilerini aktarırken akıcı bir üslup benimsemiş; çok yönlü bu kitabını araştırmacıların beğenisine sunmuştur. Kitabın te'lifi sırasında birinci elden kaynakları kullanan müellifin bu çalışması alanda araştırma yürütmek isteyenler için mihmandarlık yapabilecek nitelikte ve sağladığı güçlü bibliyografyayla da oldukça ehemmiyet kesbetmektedir. 


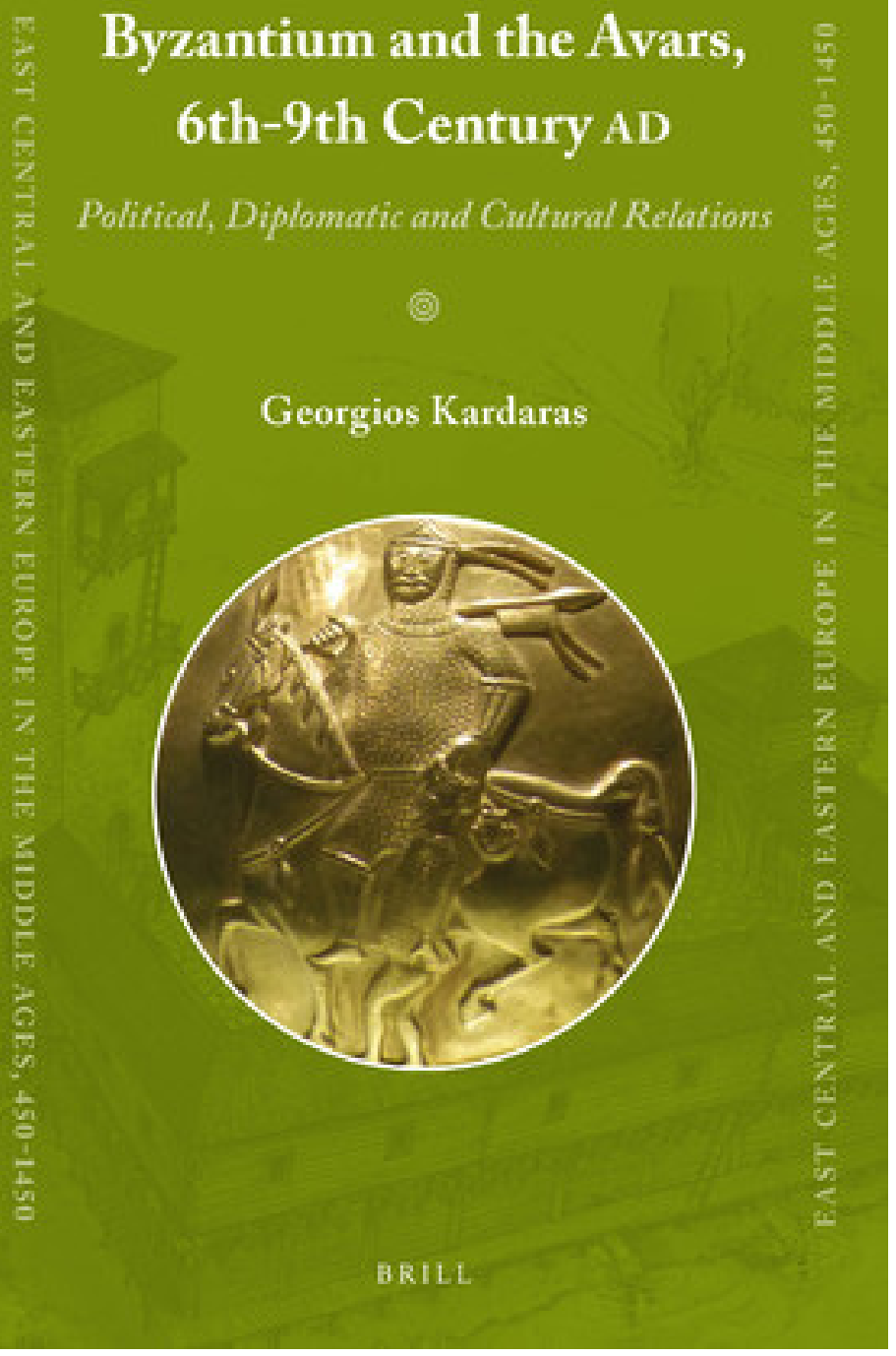


